International Journal on Emerging Mathematics Education (IJEME)

Vol. 1, No. 1, March 2017, pp. 25-40

P-ISSN: 2549-4996, E-ISSN: 2548-5806, DOI: http://dx.doi.org/10.12928/ijeme.v1i1.5736

\title{
How Do College Students Solve Logarithm Questions?
}

\author{
Tian Abdul Aziz, Puri Pramudiani, Yoppy Wahyu Purnomo \\ University of Muhammadiyah Prof. DR. HAMKA, Jl. Limau 2, Kebayoran Baru, Jakarta Selatan, DKI Jakarta 12130 \\ Email: yoppy.w.purnomo@uhamka.ac.id
}

\begin{abstract}
Abstrak
Tujuan dari penelitian ini adalah untuk menyelidiki jawaban mahasiswa dalam menyelesaikan permasalahan logaritma. Penelitian ini menggunakan penelitian kualitiatif deskriptif. Partisipan penelitian ini adalah empat belas mahasiswa Indonesia yang terdaftar di berbagai perguruan tinggi di Ankara, Turki. Mereka menyelesaikan sepuluh pertanyaan logaritma yang diklasifikasikan menurut bagian-bagian dari topik logaritma. Setelah menganalisis jawaban tertulis mereka, wawancara dilakukan untuk mendapatkan penjelasan lebih lanjut tentang strategi mereka dan kesalahan yang umum dilakukannya. Penelitian ini menemukan bahwa berdasarkan pekerjaan masing-masing partisipan dalam menjawab pertanyaan logaritma, terdapat beberapa strategi yang dapat teridentifikasi, diantaranya (a) pengolahan basis, (b) terfokus pada aturan, (c) pemisahan, (d) loncatan berpikir, dan (e) penyesuaian. Bersamaan dengan itu, beberapa partisipan melakukan kesalahan karena memiliki miskonsepsi tentang logaritma, pemahaman aritmatika yang kurang kuat, dan penyalahgunaan konsep aljabar. Implikasi dari temuan ini difokuskan pada belajar dan mengajar logaritma yang disajikan lebih lanjut di dalam artikel.
\end{abstract}

Kata Kunci: permasalahan logaritma, kesalahan umum mahasiswa, strategi mahasiswa, mahasiswa perguruan tinggi

\begin{abstract}
The purpose of the study was to investigate college students' work with logarithm questions. Qualitative descriptive research is chosen to reach the research goal. The participants of the study were fourteen Indonesian students who were enrolled at different universities in Ankara, Turkey. They worked to solve ten logarithm questions which were classified according to the contents. After analysing their written responses, interviews were conducted to obtain further explanation about their strategies and common mistakes. The study found that participants' works in dealing with logarithm questions comprised of (a) processing base, (b) holding the rule, (c) separating, (d) jumping, and (e) conditioning. Therewith, several participants made common mistake because of misconception about logarithm, arithmetical problems, and misuse of algebra concept. Implication of the finding of the study for teaching and learning logarithm were presented.
\end{abstract}

Keywords: logarithm questions, students' common mistake, students' strategies, college students

How to Cite: Aziz, T.A., Pramudiani, P., \& Purnomo, Y.W. (2017). How do college students solve logarithm questions?. International Journal on Emerging Mathematics Education, 1(1), 25-40. http://dx.doi.org/10.12928/ijeme.v1i1.5736.

\section{INTRODUCTION}

"Algebra for all " (Chazan, 1996) was a slogan which referred to the vision that mathematics curriculum offered similar chance for each student to accomplish the required task of school algebra. By reflecting this vision, unsurprisingly algebra has become compulsory subject commenced to be taught from elementary school to university level. It was reasonable policy since devoid of understanding algebra, students wi not have capability of comprehending many concepts discussed in chemistry, physics, economics, and many other areas (Usiskin, 1995). 
School algebra consists of several topics, and logarithm is a part of it. Based on the vision of "Algebra for all", hence all students, particularly in high school and university level, are in need of completing required work of logarithm. Two arguments are confirmed to describe reasons why logarithm plays important role in development of knowledge: (1) logarithm as a fundamental concept for future science, technology, engineering, and mathematics, and (2) logarithm as a tool for addressing daily life problems (Williams, 2011). Nevertheless, the aforementioned importances of logarithm are not worth with attention of research devoted to illuminating school logarithm. Either the grave scarcity of literature in the topic or researchers' intention heavily to invent the way how to introduce algebra for elementary and middle school students effectively is the primary reasons for putting aside this topic. Moreover, little research has been conducted to investigate students work with logarithm. Therefore, this situation motivates the researchers to conduct research pertaining to logarithm, particularly students' work with logarithm.

The scarcity of literatures is worsened with students' poor performance in logarithm. Generally speaking, students do not hold the concept of logarithm very well (Williams, 2011). As a consequence, they cannot cope with logarithm questions properly. This fact is prevalent and can be proved by teachers who teach logarithm in their mathematics classroom. To relieve it, teachers are necessary to understand students' work when solving logarithm questions. By investigating students' work with it, teachers not only gain description of students' common mistakes but also students' strategies. Students who do not possess strong concept of logarithm tend to make mistakes, whereas students who have good understanding of the concepts are able to solve the problem by means of various strategies.

Studies to investigate students' work on solving logarithm problem, particularly exploring common mistake that students made have been conducted. Study conducted by Chua and Wood (2005) found that overwhelming majority of errors students made were caused by over-generalisation of algebra, that is, students considered that all the concept of variable in algebra could be applied immediately in concept of logarithms. Students' common mistakes were also investigated by Hoon, Singh, and Ayop (2010) such as failed to memorize the definition of logarithms, incorrect use of the properties of logarithm, confusion with the previous knowledge, lack of knowledge of selecting the suitable base to be used when modifying the base of logarithm, and misunderstand with the instructional word in logarithm questions. In other study, Williams (2011) employed the framework of logarithms i.e. logarithm as object, logarithm as process, logarithm as function, and logarithm in contextual problems to come accross students misunderstanding in solving logarithm questions.

With respect to students' strategies to overcome logarithm questions, Berezovski and Zazkis (2006) described students' process emphasized on procedural approach and reliance on the rule. They revealed that strategies students performed were in relation to the interpretive framework for logarithm and logarithmic function, that is, logarithm and logarithm expression as numbers, operational meaning of logarithm, and logarithm as function. They also added that students' work with logarithm questions was not accompanied with understanding the meaning of the concept.

However, substantial amount of previous studies tended to investigate work of high school students on logarithm questions (Chua \& Wood, 2005; Hoon et al., 2010; Panagiotou, 2011). Despite an increased attention of studies in logarithm for high school students last days, it is surprising that so little, even no, empirical study has

IJEME, Vol. 1, No. 1, March 2017, 25-40 
actually been conducted for investigating college students work with logarithm. College students, in fact, use logarithm in calculus courses and other upper-level mathematics, hence proficiency in logarithm cannot be neglected absolutely. Exploring their common mistakes when solving logarithm questions is in need of more investigation. Moreover, what remain to be explored is diversity of their' strategies in solving logarithm questions.

A study of investigation of students' works in solving logarithm problem is significant for several reasons. First, recognizing college students' common mistakes when solving logarithm problem guides teachers in high school level to provide teaching and learning methods encouraging students to understand the concept for long term instead of short term just for passing exam. Second, understanding college students' common mistakes provides information about students' shortcomings in mastering concept related to logarithm i.e. arithmetic, variable, quadratics equation, etc., and teachers may take those things into consideration by preparing students with strong prerequisite knowledge. Third, various college students' strategies when working on logarithm allow us to replicate it and teach it to students in high school level so that they are able to solve any logarithm question effectively and properly.

The purpose of this study is to investigate strategies of fourteen college Indonesian students who are enrolled at two different universities in Ankara while trying to deal with logarithm questions. The study seeks explanation concerning their strategies as well as common mistakes that they made when solving logarithm problems. Therefore, at this stage in the research, the students' work will be generally described as students' strategies in terms of written form and their common mistakes. In addition, the study deal with analysing participant' written response of proposed questions, even though it would be gain more appropriate result if think aloud technique was conducted.

\section{RESEARCH METHOD}

To reach the goal of study, the researchers conducted qualitative descriptive research. This was compatible with what Creswell (2014) described concerning characteristics of qualitative research, several of them were natural setting, participants' meaning, and theoretical lens. Therefore, to achieve the goal of this study, we did not provide any treatment for participants, yet we gained rich information about participants' perspective of the topics, and we analysed the result by employing existing the conception of logarithm.

\section{Participant}

Purposive sampling method were used to select the participants of the study. To facilitate the researchers in gathering and communicating, the participants of this study were fourteen male Indonesian students who have graduated from different secondary schools and enrolled at two different universities in Ankara, Turkey. The participants of the study were: (1) ten students who are attending language preparatory course: six of whom are in Turkish language course, and four of whom are in English language course; and (2) four students who have been already attending course in their department: two of whom are in department of mathematics, and the rest are in department of chemistry department and department of mining engineering. All of them were new high school graduate so they did not attend any further mathematics courses. Their mathematics knowledge were above average since 
to be accepted in Turkish university the minimum score of SAT (Scholastic Aptitude Test) for mathematics was 600 out of 800 .

Subsequently, interview was conducted to five participants who were selected purposively. The researchers selected them by considering their written works as several of them possessed similar strategies, mistakes, and misconceptions. Participants who had distinct approaches to the questions were selected, so that rich categorizations were obtained.

\section{Logarithm Questions}

Ten questions of logarithm used in this study were designed by considering all contents in logarithm: definition of logarithm, properties of logarithm, numeric manipulation, symbolic manipulation, logarithmic equation, graphing of logarithmic function, table of logarithm, logarithm function, and real-world problem. Multiple contents enabled the researchers to illustrate how participants work with those contents. Regardless of piloting the questions, most of which taken and selected from previous studies and mathematics textbooks with some revisions according to the focus of this study. With respect to validity of the instruments, the reserchers consulted it to two experts in mathematics education. Improvement and approval were obtained.

\section{Procedures}

The study involved compiling data through a test and interviews. Therefore, the data consist of two types: written data and interview data. The test was administered to 14 college students from two universities on two successive days. Participants were asked to accomplish the ten questions within one hour. However, several of them requested to be given additional time. For them, the researchers gave 15 minutes. Then, analysing participants written response were conducted on the day after the test was administered.

After analysing the participants' written response, on the next day the researchers conducted interview to gain deep information and justification concerning students' work by asking them to shed light on their strategies and concepts used while dealing with the questions as well as to carry out member checking. To do this, protocol interview questions were prepared before hand to guide the researchers during interview. When interviewing, the similar logarithm questions were used so as to participants could provide deep and more explanation about their answers.

\section{Data Analysis}

The result of participants answer sheets were compiled and there was no rejection for students who did not accomplished the questions properly or completely. Therefore, the researchers accepted whatever the condition of participants' written responses, in as much as the most important thing was their work. The participants' written responses were labelled sequentially from L1 to L14 in order to facilitate the researchers in identifying their work during analysis and fulfilling ethical considerations. Then, detail analysis of each item questions was conducted.

Determining sort of participants strategies were carried out by employing three sequential steps. The first step was to evaluate each participants' work on solving certain logarithm questions item by item. In other words, we analysed each response on similar question initially in order to notice the difference among them easily. The differences ranged in how participants hold the rules, choose appropriate tools,

IJEME, Vol. 1, No. 1, March 2017, 25-40 
execute sequential step, and apply writing technique to assist them answer the questions. The second step was to categorize, that is, the process of compiling similar strategies and labelling it. Then, the third step was to attach explanation which consisted of revealing actual reason and related examples from participants' perspectives which was obtained from the data.

With respect to participants' common mistake, we conducted analysis by evaluating each question according to the contents of logarithm. Since we applied seven contents, thus initially we investigated all participants' response towards contents one by one. Then, we listed all participants' mistakes and categorized it according to its commonality. Subsequently, we tried to gain more information concerning participants' common mistakes by presenting the actual reasons and that of examples from the data.

In determining sort of participants' strategies and their common mistakes, the researchers categorized it based on their written responses. Therefore, categorization was conducted inductively. The possible categories were discussed to reach common categories. Consultation to two experts in mathematics education was conducted and evetually agreement was obtained.

In this study, trustworthiness could be describe by means of dependability, transferability, credibility, and confirmability (Guba \& Lincoln, 1982). Rich and thick description of participants as well as the interview questions and data collection procedures were described. In this study, interviews were audio recorded so that there was no any losing information. Theoretical purposive sampling and thick description were undertaken to ensure transferability. Triangulation also was conducted in which the researchers used multiple methods of data collection such as participants' written works, interview, probing questions, and literature review. In addition, peer debriefing was evaluated after the completion of transcribing. Eventually, reasons for formulating the study in a certain way, decisions during the study, rationale behind the decisions, and quality of the decisions were presented.

\section{RESULTS AND DISCUSSION}

The results of the analysis delivered valuable information concerning participants' strategies and common mistakes while working to address the logarithm questions. Therefore, the researchers divided the explanation into two sections according to the focus of our study, all of which will be elucidated by presenting important data (participants' written responses or interviews). Therewith, the four conceptions of logarithm were embedded as fundamental discussion in detail description of several participants' common mistakes.

\section{Students' Strategies}

Participants' strategies to solve logarithm questions generally speaking differed from participant to participants according to the sort of questions as well as their ability. Participants who had more experience working with logarithm performing effective computation and establishing proper reasons confidently. Whereas, participants who were lack of experience or could not retrieve the rules tend to guess the answer, present incorrect rules, and even leave the questions blank. On the ground of analysis of all participants' written responses, we discovered five strategies that they had performed which varied according to the type of questions: processing base, holding the rule, jumping, separating, and conditioning. In this case, the researchers 
derived the strategies from participants who performed computation in correct manner, and we get rid of incorrect responses.

\section{Processing Base}

Most of logarithm questions were dealing with base. In order to perform further calculation of logarithm, participants had to pay more attention to that of base. Generally speaking, according to the work, they were undertaking two activities dealing with the base: modifying base and selecting appropriate base.

The first activity was modifying base. We could say that the pivotal process in logarithm was base modification. It was reasonable statement since in order to perform further computation, each expression had to consider identical base. Question $4 \mathrm{a}, 4 \mathrm{~b}$, and 9 were proposed to examine participants' strategies to alter the base. While the second activity was selecting appropriate base. The way how participants dealt with the process of selecting appropriate base can be seen obviously in question 7. Participants answered it by choosing different bases, most of whom applied three as the base, and only one of whom used two as the base. For those who picked three as the base (see figure 1.a.), they argued that they had tried to employ other base (i.e. two and five) and they faced difficulty. Besides, some of them confidently considered that using two or five as base could not reach the solution. Furthermore, in order to choose suitable base, they revealed that before answering the question they could imagine what steps would be carried out and guessed what answer would be obtained. However, L10 decided to solve the question by making use of base 2 (see figure 1.b.), he then argued that, "since 2 is the smallest among 2, 3, and 5 it's better to use basic 2 as common". To do this, he attached hidden properties by noting that $\log _{2} 5=\log _{2} 3 \cdot \log _{3} 5$. Also, he added that the selecting appropriate base is drawn from his experience.

$$
\begin{aligned}
& \log _{15} 20=\frac{\log _{3} 20}{\log _{3} 15}=\frac{\log _{3} 2+\log _{3} 5+\log _{3} 2}{\log _{3} 30-\log _{3} 2} \\
& =\frac{\frac{1}{a}+b+\frac{1}{a}}{\log _{3} 3+\log _{3} 5+\log _{3} 2-\log _{3} 2} \\
& =\frac{\frac{1}{a}+b+\frac{1}{a}}{1+b+\frac{1}{a}-\frac{1}{a}}=\frac{\frac{2}{a}+b}{1+b}
\end{aligned}
$$

$$
\begin{aligned}
& \log _{15} 20=\frac{\log _{2} 20}{\log _{2} 15}=\frac{\log _{2}\left(2^{2} \cdot 5\right)}{\log _{2}(3 \cdot 5)} \\
& =\frac{\log _{2} 2^{2}+\log _{2} 5}{\log _{2} 3+\log _{2} 5}=\frac{2 \log _{2} 2+\log _{2} 5}{\log _{2} 3+\log _{2} 5} \\
& =\frac{2 \cdot 1+a b}{a+a b}=\frac{2+a b}{a(1+b)}
\end{aligned}
$$

Figure 1. Participants' Strategies to Select Appropriate Base

Holding the Rule

Holding the rule referred to strategies of participants who followed the existing properties to perform calculation when solving logarithm questions. The strategies could be noticed explicitly when several participants decided to attend the properties. For instance, student L10 tried to solve the fourth questions $\log _{4} x+\log _{8} x^{2}$ by 
performing calculation as $\frac{1}{2} \log _{2} x+\frac{1}{3} \log _{2} x^{2}=\log _{2}\left(x^{\frac{1}{2}} \cdot x^{\frac{1}{3} \cdot 2}\right)=\log _{2}\left(x^{\frac{1}{2}+\frac{2}{3}}\right)$. Here, the participant brought the coefficients of logarithmic expression to be put as exponent of $x$ instead of making effort to provide the common logarithmic expression $\left(\log _{2} x\right)$ by moving the exponent of 2 into coefficient. He considered the product property of logarithm. Therefore, he was likely to possess the conception of logarithm as procedure or process.

In contrast, other participants tended to perceive that logarithmic expression as variables or object rather than process or procedure. Therefore, participant L4 performed $\frac{1}{2} \log _{2} x+\frac{2}{3} \log _{2} x=\frac{3+4}{6}\left(\log _{2} x\right)=\frac{7}{6} \log _{2} x$. This case was compatible with what Kaur and Sharon found in their study (1994) which claimed that students considered that log is common factor, thus the students simplify the expression $\frac{\log 16-\log 8+\log 4}{\log 3}$ to $\frac{\log (16-8+4)}{\log 3}$. If students did not pay attention the proper use of conception of logarithm as object or variable, they might generalize to other operation such as cancelling log.

\section{Jumping}

Jumping referred to respondents' strategy to discard logical procedure of computation by skipping one or more steps due to the practical reason or imagination of procedures within mind. It could be discerned easily in most participants work such as what participant L2 had performed as $\log _{4} x+\log _{8} x^{2}=\frac{1}{2} \log _{2} x+\frac{2}{3} \log _{2} x$. By processing application of properties of logarithm in his mind, he omitted one up to two steps. Therefore, without carrying out all procedures sequentially he was likely to write the result immediately. This strategy mostly was used by participants who hold the properties strongly and possess experience in dealing with the problem.

R: You wrote that $\log _{9} \sqrt[3]{x^{18}}=\frac{\frac{18}{3}}{2} \log _{3} x$, why did you answer directly without any process?

L2: because I have already seen the process by using properties of logarithm in my mind, and no need to write it because it is wasting time.

In the relation to mathematics school, procedures referred to computational methods and students possesed to be promoted to appreciate the role of procedure in mathematics (Star R., 2005). We could recognize students' application of procedures through their writing. So to speak, writing was a communication tool to discern respondents thinking process (Menary, 2007) in their effort to solve the problem. Therefore, even though students also had to comprehend how to do calculation or carry out mathematical procedures efficiently on the ground of aforementioned explanation jumping could be seen as breaking the regularity of computational methods.

One of the disadvantages of jumping was that participants tended to perform calculation hastily and it made them did not have enough time to crosscheck the processes. This was compatible with participants' explanation concerning his wrong 
answer due to the jumping strategies he performed. He did wrong calculation $\frac{\frac{18}{3}}{2} \log _{3} x=\frac{36}{3} \log _{3} x$, he admitted that he disregarded of writing the process or procedure explicitly.

\section{Separating}

Separating referred to participants' strategies to overcome logarithm questions by setting apart the calculation or computation from procedural steps for the sake of simplifying the process and assisting participants decompose the question, and the results were combined at the end of calculation. For instance, participant L6 made effort to address Question 7 by separating calculation. He performed calculation of determining $\log _{3} 20$ and $\log _{3} 15$ in terms of $a$ and $b$ aparting from main calculation.

Then, the result of $\log _{3} 20$ and $\log _{3} 15$ were put together eventually. Respondent L6 acknowledged his reason towards his strategies, "My reason is that the question need to be broken into several equations in order to facilitate the solution so that the question will be addressed easily".

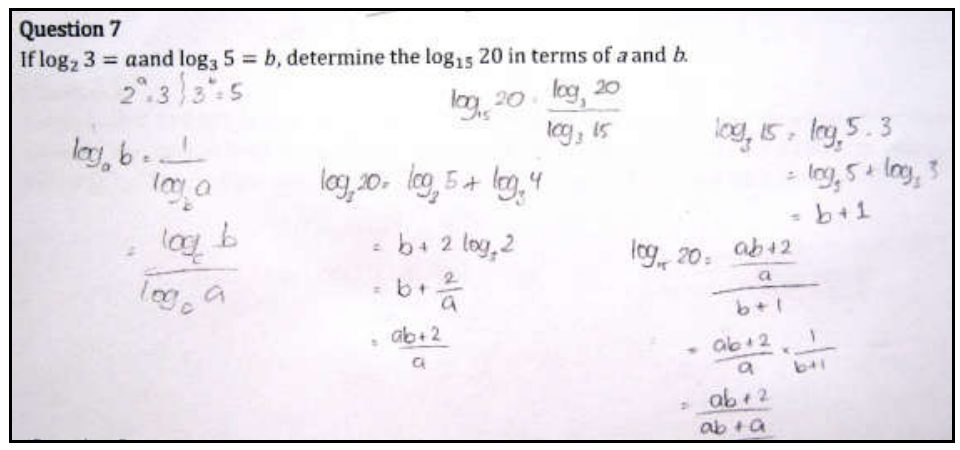

Figure 2. L6's Example of Separating

\section{Conditioning}

This types of strategy could be found evidently when participants solved logarithmic equation question. Making condition referred to respondents' strategy to establish provision restricting possible result by considering definition of logarithm. It comprised of two categories: initial conditioning and conditioning at the end. Initial conditioning was conducted by student L10 which aimed at framing the domain in order to guide him locate the likelihood of obtained answers correctly and prevent him from ignoring to select satisfied value in the end of calculation.

L10 : We have to be careful with the value of $x$. We cannot take both of them.

$R \quad:$ So, you check the condition at first, don't you?

L10 :Yes, because the values of $x$ have to be less than three and less than two.

$R \quad:$ How if we check the condition at the end of calculation? Is there any effect to your result?

L10 : I think, it depends on our ways, if we do not make condition it initially we will immediately conclude that that both of the number satisfy with the equation and it is wrong since there is no logarithm of negative number. So, making condition at the beginning, I think, is more comfortable for me. 
In contrast, most of the participants made condition after they had found the answers, and some of whom perceived that the two roots of a quadratics equation were the intended answers. Thus, if participants did not consider definition of logarithms, they would decide that both values can be accepted as values to substitute the variable $x$. Conditioning at the end was likely to open possibility for participants to ignore the provision or definition of logarithm. This ignorance might be caused by forgetfulness or misconception. So to speak, initial conditioning had more benefit than conditioning at the end.

\section{Students' Common Mistakes}

\section{Definition of Logarithm}

The first question proposed to participants was pertaining to definition of logarithm. Here, participants were asked to communicate their understanding with respect to provisions or restriction of each elements in logarithmic notation $\left(\log _{a} b=c\right.$ ), to wit, the reasons why the value of $a$ had to be positive number and not equal to one, and the value of $b$ had to be positive number. Participants were also asked to determine the possible value of $c$. However, most of participants could not spell out it properly. They seemed to ignore this provision and admitted that they had never be taught about it in their high school. Only several participants could provide the proper answer such as what L10 wrote to describe his reason.

" $\log _{a} b=c \rightarrow a^{c}=b, a$ cannot be equal to one because if it is 1 , all function will be same (i.e. 1 to the power of all real numbers is 1). Also, a has to be positive because the base of exponential function has to be positive. If it is a function $f(x)=\log _{a} x$, then it is the inverse of exponential function (which has range in positive real numbers) so the logarithm function must have domain in positive real numbers (i.e. $x>0 \rightarrow b>0$ )"

He provided the reason through presenting connection between concepts of logarithm and exponential function. His initial condition was $\log _{a} b=c \rightarrow a^{c}=b$, hence he possessed common conception that logarithm was inverse of exponent. However, he did not explain the subsequent question pertaining to the feasible value of $c$. Participant L6 tried to express his argument towards the value of $c$, he revealed that, "...the value of $c$ is can be either positive or negative, since $c$ is exponent, thus it cannot influence the value of $b^{\prime \prime}$. Essentially, L6 made effort to decide the value of $c$ by considering relation to $b$. He held similar conception about relation between logarithm and exponent. Likewise, participant L14 proposed the same reason, yet he established a numerical example to ensure his judgement.

With respect to logarithmic notation $\log _{a} b=c$, the participants also had various ways to express it. However, most of them could not express it properly.

i. $\quad R$ : How do you read this logarithmic notation? (Researcher point out $\log _{a} b=c$ )

L2: $\log a b c$

$R:$ What?

L2: $\log$ a b equal to $c$

$R$ : Are you sure?

L2: Log $b$ with base-a equal to $c$. But I think it is not important to express it when solving the problem. 

ii. $\quad R \quad$ :How do you read this? (Researcher shows $\log _{a} b=c$ )
L10 : $\log a$ of $b$
$R \quad$ : Are you sure?
L10 : I am not sure. I forget how to express this.
$R \quad$ : When you were student in high school, how did express it?
L10 : As far as I remember, $\log a$ of $b$, since If I say $\log a b$, it might become multiplication of $a$ and $b$.

According to interview result, the improper articulation of logarithmic notation could be caused by lack of teachers' intention to guide students in expressing it correctly and their perception that expressing logarithmic notation was not important. Numeric manipulations

One question was devoted to examining participants in coping with numerical manipulation within logarithm context. The whole majority of students did not encounter difficulty. However, several participants performed incorrect calculation due to his carelessness and unconsciousness. For instance, participant L9 performed wrong calculation as $\log _{3} 27=9$.

$T \quad$ :You said that logarithm of $b$ with base-a equal to $c$ can be expressed $a s a^{c}=b$

L9 :yes...

$T \quad$ : and your answer is 9 , are you sure?

L9 : no, it is wrong, it should be 3.

$T \quad:$ So, why did you answer this question by 9 ?

L9 : I do not know. I didn't realize it and I was careless.

\section{Symbolic Manipulation}

Five distinct questions pertaining to symbolic manipulation in logarithm were arranged according to its difficulty level aimed at assessing participants' ability to employ the properties of logarithm and its conceptual framework about logarithm. Several participants showed their inability to solve the questions since it consisted of variables which made them in trouble.

When participants were asked to solve the question $3 \mathrm{~b}$, one participant (L9) undertook calculation as $\log _{2} x y-\log _{2} y^{2}+\log _{2} 2=\log _{2}\left(x y-y^{2}+2\right)$. In this case, he perceived that $\log _{2}$ as a variable. Therefore, it appeared that he possessed the conception of logarithm as object rather than process. This also occurred when participant wrote $\log _{15} 20=\frac{\log 20}{\log 15}=\frac{\log _{2} 4}{\log _{2} 3}=\frac{2 \log _{2} 2}{\log _{2} 3}=\frac{2}{a}$.

Understanding the use of bracket also was necessary for participants to decide whether certain number was included or not. For instance, the number 1 in $\log _{2} y+1$ was not included in logarithmic expression, yet several students might consider that 1 was included. Student L5 made a mistake about this case. He certainly claimed that the number one was included in logarithmic expression, thus unsurprisingly he answered

the problems as $\log _{2} x y-2 \log _{2} y+1=\log _{2} x y-\log _{2}(y+1)^{2}=\log _{2} \frac{x y}{y^{2}+2 y+1}$.

IJEME, Vol. 1, No. 1, March 2017, 25-40 
Participants' misconception of the word "simplify" also caused diversity in their' responses. Some of them revealed that $\log _{2}\left(\frac{2 x}{y}\right)$ was the simplest form, whereas the other argued that $\log _{2} 2 x-\log _{2} y$ or $1+\log _{2} \frac{x}{y}$ was the answer.

1. $R \quad$ : What do you mean the word "simplify"?

L14 : Since the theme of these questions is about logarithm, if we asked to simplify so the result of the problem is the simplest one which is in logarithmic form.

2. $R$ : Which one of the following statements is the simpler form? (Researcher point out $\log _{2}\left(\frac{2 x}{y}\right)$ and $\log _{2} 2 x-\log _{2} y$ )

L2 : This one (he shows $\log _{2}\left(\frac{2 x}{y}\right)$ ) because it is the simplest.

$R \quad:$ OK, but why did you expand it?

L2 : Yes, I expanded it.

$R \quad$ : So, which one is the simpler one?

L2 : (he changes his mind) Yes, this is the simplest one (he indicates $\log _{2} 2 x-\log _{2} y$ )

$R$ : Why, can you give me a reason?

L2 : I think $\log _{2}\left(\frac{2 x}{y}\right)$ is strange, so I changed it into familiar form.

In symbolic manipulation, most participants also encountered difficulty in arithmetic process such as $\frac{1}{2} \log _{2} x+\frac{2}{3} \log _{2} x=\frac{1}{2}+\frac{2}{3}=\frac{3+2}{6}=\frac{5}{6} \log _{2} x$, and $\frac{\frac{18}{3}}{2} \log _{3} x=\frac{36}{3} \log _{3} x$.

\section{Logarithm Equations}

Diversity of participant strategies and answers could be discovered in this question. It consisted of multiple concepts that participants were necessary to master beforehand such as definition of logarithm, properties of logarithm, quadratic equation, as well as computation. The following were several examples of participants work on solving the question.

In figure 3.a. the participant who answered such strategy was likely to hold the conception that $a \cdot b=0 \Rightarrow a=0 \vee b=0$ and by taking it for granted he generalized into any cases, particularly logarithm and addition. "Actually, I don't know the true way to solve this question but I use my own way. Since the equation equal to one, thus I separate it and each equation equal to one". Thus, he thought that $a+b=1 \Rightarrow a=1 \vee b=1$. Moreover, without establishing any explanation he wrote that the value of $x$ equal to 90 (he multiplied both of the obtained value). The reason was that he possessed an outlook that every question has single solution. In other word, variable in his mind stood for a specific unknown number. 


\begin{tabular}{|l|l|l|l|}
\hline $\log _{12}(3-x)+\log _{12}(2-x)=1$ & $\left(6-3 x-2 x+x^{2}\right)=1$ & $x^{2}-5 x-6=0$ \\
$\Rightarrow \log _{12}(3-x)=1$ & $\Rightarrow \log _{12}(2-x)=1$ & $x^{2}-5 x-6=1$ & $(x-2)(x-3)=0$ \\
$12=3-x$ & $12=2-x$ & $x(x-5)=7$ & $x_{1}=2, x_{2}=3$ \\
$-9=x$ & $10=-x$ & $x=7$ & \\
& $-10=x$ & $x=12$ & \\
$x=90$ & &
\end{tabular}

(a)

(b)

(c)

Figure 3. Example of Participants' Work on Logarithmic Equation Question

In figure 3.b., a participant disregarded that $a=b \Leftrightarrow \log _{c} a=\log _{c} b$ and performed direct calculation without modifying the number in the left side into logarithmic expression as $\log _{12} 12$. Also, he performed incorrect factorization similar to what the previous participant did. He made this fundamental mistake and it was due to lack of understanding the rule of logarithm and finding two roots of quadratics equation. Meanwhile, in figure 3.c. a participant also had difficulty with factorization. For college students, actually, it was easy calculation, yet due to lack of experience in factorizing properly, carelessness as well as negligence of checking, they could make mistakes.

\section{Graph of Logarithm and Logarithmic Function}

The conception of logarithms as process was found in logarithmic function. As logarithm was the invers of exponent, thus logarithmic function was the invers of exponential function. Most of the participants made mistake when sketching the graphs of $f(x)=2^{x}$ and $f(x)=\log _{2} x$. The mistakes ranged among overgeneralization (L14), incompleteness (L6), and not finding relationship.

Over-generalization was participants' mistake when they sketched a graph properly in certain quadrant, yet since they perceived that the graph was symmetry so they generalized it to another quadrant (figure 4). Incompleteness occurred when participants disregarded negative domain of $x$ and tended to deal only with positive number. It might happen since in listing all possibility, students only substituted $x$ only with positive value (figure 5). Inability to discern and discover relationship between the two graphs also were encountered by participants.

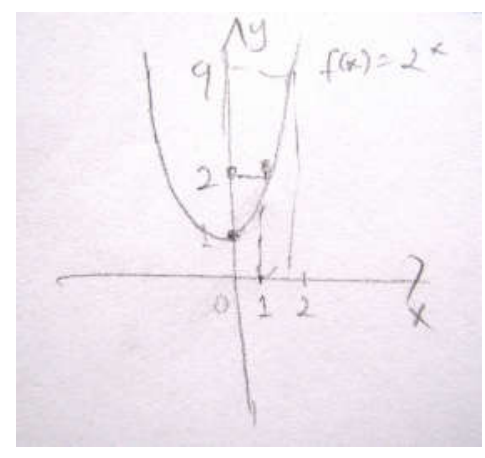

Figure 4. Example of Over-Generalization

IJEME, Vol. 1, No. 1, March 2017, 25-40 


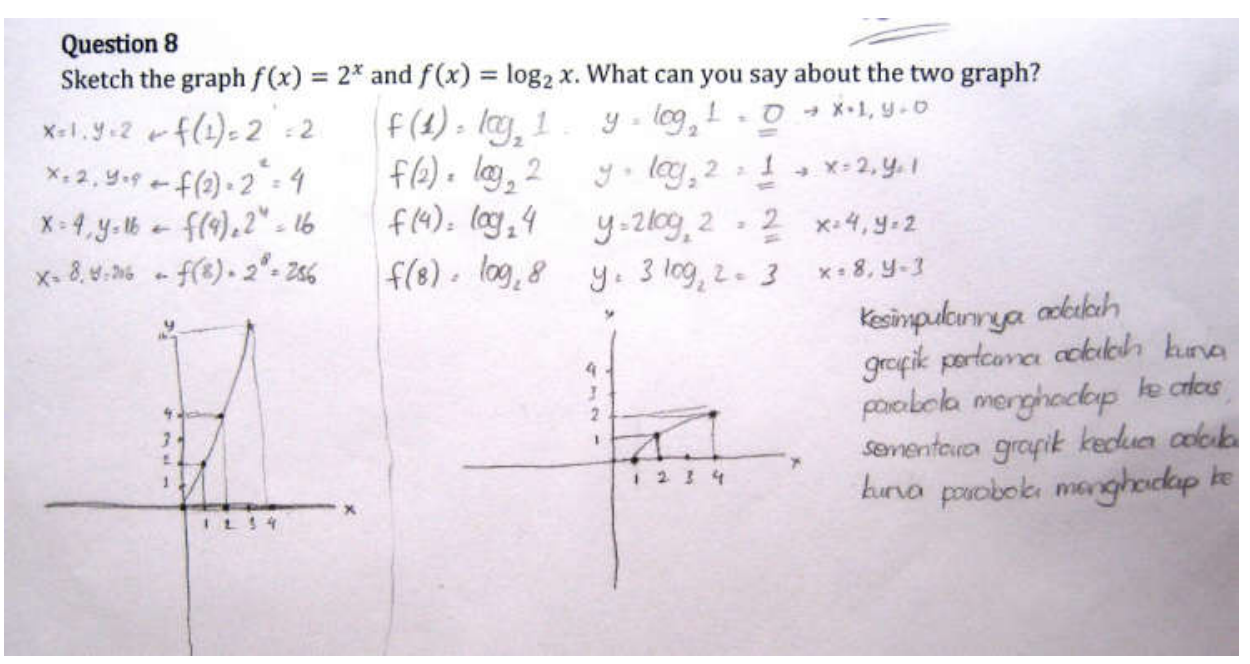

Figure 5. Example of Incomplete

The result of this study initially highlighted various participants' strategies such as processing base, holding the rules, jumping, separating, and conditioning to solve logarithm questions according to that of contents. It enabled us to make connection to the conceptions of logarithm. Processing base referred to participants' view that logarithms as structure. When two logarithm expressions were operated, participant saw the structure of logarithm, particularly the base. Therefore, teachers should provide an initial explanation of logarithm by focusing on the importance of base. Also, teachers should ensure students that there is no operation can be performed in base, except operation of power. For example, one participant expressed that $\log _{15} 20=\log _{3.5} 20$.

Holding the rules meant that participants discerned that logarithms as generalization and they benefited from those rules to guide them accomplishing logarithm questions. This strategy also led participants to understand that logarithms was not a variable but as generalizer. In order students to perform holding the rules strategies properly, the effective way was to have students understand all properties. The rules itself had be taught meaningfully by providing logical proof so that students did not just memorize it.

Jumping, separating, and conditioning indicated that participants held the conception of logarithm as procedure for solving questions. Teachers could take those strategies into consideration and present it so that his/her students could have multiple alternative ways to handle logarithm questions. However, the advantages and disadvantages of those strategies also should be described properly.

Also, the result of this study pointed to scrutiny participants' common mistakes when addressing logarithm questions. Initially, we proposed question related to definition of logarithm. By doing so, we expected participants to be able to evaluate their comprehension about the requirements of each elements of logarithmic notation $\left(\log _{a} b=c\right)$. It was likely that participants did not have strong fundamental understanding concerning logarithmic notation. Therefore, teachers at the first occasion in introducing the topic should embed intensively the definition of logarithm within students' mind.

Also, we considered that the way how students expressed the logarithmic notation was crucial. After paying attention to several participants when they read the 
notation, it was apparently that they were not able to provide proper verbal expression. This finding was in line with what Hoon et al. (2010) had claimed in their study. It might be due to participants' inability to get the definition of logarithm and build connection to exponents. In this case, we made use of common conception that logarithm was the invers of raising to a power (exponents), thus we did not confirm the historical development of logarithm which emphasized the concept of geometric and arithmetic sequences (Fauvel, 1995; Katz, 1995; Panagiotou, 2011) as the basic theme when introducing logarithm. So, for instance, teachers should provide powerful explanation repetitively that $a^{c}=b$ can be expressed as $\log _{a} b=c$ by using numerical example such as $2^{3}=8 \Rightarrow \log _{2} 8=3$. When presenting the logarithmic notation and also that of numerical example, teachers should guide student to articulate "logarithm of $b$ with respect to the base- $a$ equals to $c$ " or logarithm to the base a of b" (Hoon et al., 2010).

Executing numerical manipulation and symbolic manipulation in logarithm question had distinct sense, while participants tended to perceive that the former was easier than the latter or students encountered difficulty with high level questions. Chua and Wood (2005) found that most students seemed to be able to solve routine calculations than higher levels of problems. However, the core of the problem was participants' ability to hold properties of logarithm as well as experience to solve questions. If they strongly memorized as well as made sense of the rules by experiencing in long term, they would execute the questions effectively in proper manner. Therefore, students' common mistakes in both manipulation could be relieved by presenting learning and teaching method which encourage students not to memorize the rules but to understand it meaningfully.

Teachers should realize students' shortcomings in accomplishing logarithmic equation questions. The possible reason might be that each topic in school algebra is presented in separated section. Also, students might put the rules in the "shelf" after learning logarithm without practicing it further. In Indonesia, the topic of logarithms was specialized topic provided for $10^{\text {th }}$ grade students. It is presented after the topic of exponential function. Understanding of the topics of exponents is prerequisite of dealing with logarithms. In other words, mastering prerequisite topics for logarithm plays significant role in helping students deal with the concept of logarithms. Therefore, teachers should evoke students understanding concerning previous topics by constructing a bridge at the beginning of lesson so that students are able to grasp the unity of and interconnected mathematical concepts.

Participants seemed to be lack of conception of logarithms as structure. They did not see structure between $\log _{12}(3-x)+\log _{12}(2-x)$ in the left side and the number 1 in the right side. Conception of logarithms as number also was not possessed by participants. In this case, several participants did not consider that the number 1 could be represented as logarithm $\log _{12} 12$. Participants' perspective towards the instructional word such as "solve" and "find the values" also brought about incorrect process and solution. Therefore, teachers should provide explanation about such key instructions to students.

Participants' understanding of definition of logarithm coupled with that of view of variable within logarithmic expression were fundamental concepts to draw proper graph of logarithmic function. Definition of logarithm cannot be isolated from logarithmic function since in order to constrain the value of each element in logarithmic notation can be done easily by relating it to that of graph. In addition to 
graph of logarithm, it comes to the conception that logarithm as function. The values of $x$ in $y=\log _{2} x$ differ from negative to positive real numbers (we call this as domain of function), and the range are real numbers greater than zero. Over-generalization of and incomplete in drawing graph rendered by participants can be omitted by teachers if they provides a proper way how to construct a graph by using technological assistance.

Conception of logarithm as number, structure, procedure, function and a tool should be contrasted evidently in various ways since if students apply it in incorrect occasion it will impact to their strategies and solution. What can be drawn from this description is that students should manage their mind flexibly concerning various conceptions of logarithms. Therefore, teachers should provide different questions which encourage students to use their mind flexibly. Lastly, teachers also should guide students to check their work after achieving the solution of any questions, since in this study most of participants performed incorrect calculation due to carelessness and negligence of crosscheck.

\section{CONCLUSION}

On the ground of previous sections, it appeared that students used various strategies to solve the logarithm questions and the common mistakes which participants made in this study were caused by inflexibility of the conception of logarithm, carelessness of arithmetical calculation, and misuse of algebra concept. Generally speaking, in this study participants' strategies to solve logarithms questions and their common mistakes were framed in the conception of logarithm. For further study, it will be necessary to investigate how students manage flexibility of the conceptions of logarithm so that students are able to solve different problems properly.

\section{REFERENCES}

Berezovski, T., \& Zazkis, R. (2006). Logarithms: Snapshots from two tasks. International Group for the Psychology of Mathematics Education, 145.

Chazan, D. (1996). Algebra for all students? Journal of Mathematical Behavior, 15, 455477.

Chua, B.L., \& Wood, E. (2005). Working with logarithms: students' misconceptions and errors. The Mathematics Educator, 8(2), 53-70.

Creswell, J.W. (2014). Research Design: Qualitative, Quantitative, and Mixed Methods Approaches. Research design Qualitative quantitative and mixed methods approaches. https://doi.org/10.1007/s13398-014-0173-7.2.

Fauvel, J. (1995). Revisiting the history of logarithms. In F. Swetz, J. Fauvel, O. Bekken, B. Johansson, \& V. Katz (Eds.), Learn from the masters (pp. 39-48). Washington, DC: Mathematical Association of America.

Guba, E.G., \& Lincoln, Y.S. (1982). Epistemological and methodological bases of naturalistic inquiry. Educational Communication \& Technology, 30(4), 233-252. https://doi.org/10.1007/BF02765185.

Hoon, T.S., Singh, P., \& Ayop, S.K. (2010). Working with Logarithms. Malaysian Education Dean's Council Journal, 6(6).

Katz, V.J. (1995). Napier's logarithms adapted for today's classroom. In F. Swetz, J. 
Fauvel, O. Bekken, B. Johansson, \& V. Katz (Eds.), Learn from the masters (pp. 4955). Washington, DC: Mathematical Association of America.

Kaur, B., \& Sharon, B.H.P. (1994). Algebraic Misconceptions of First Year College Students. Focus on Learning Problems in Mathematics, 16(4), 43-58.

Menary, R. (2007). Writing as thinking. Language Sciences, 29(5), 621-632. https://doi.org/10.1016/j.langsci.2007.01.005.

Panagiotou, E.N. (2011). Using history to teach mathematics: The case of logarithms. Science \& Education, 20(1), 1-35.

Star R.J. (2005). Reconceptualizing Procedural Knowledge. Journal for Research in Mathematics Education, 36(5), 404-411. https://doi.org/10.2307/30034943

Usiskin, Z. (1995). Why is Algebra Important To Learn? American Educator.

Williams, H.R.A. (2011). A Conceptual Framework for Student Understanding of Logarithms. Brigham Young University. Retrieved from http://scholarsarchive.byu.edu/etd/3123. 